Naumenko Stanislav. Specificity of working with gifted primary school students in China. Journal of Education, Health and Sport. 2020;10(8):623-634. eISSN 2391-8306. DOI http://dx.doi.org/10.12775/JEHS.2020.10.08.074

https://apcz.umk.pl/czasopisma/index.php/JEHS/article/view/JEHS.2020.10.08.074

https://zenodo.org/record/5550742

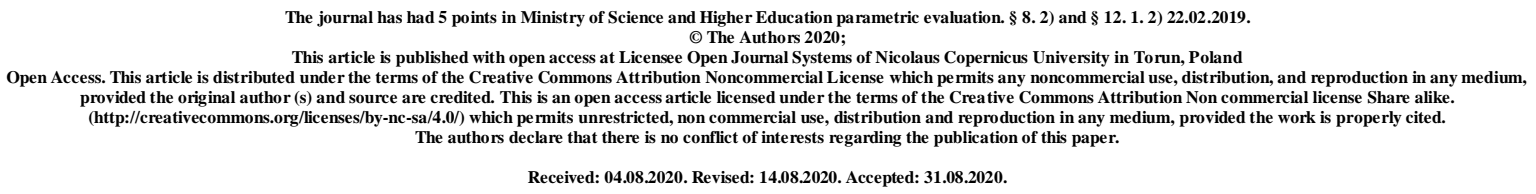

UDC 378.147: 372

\title{
SPECIFICITY OF WORKING WITH GIFTED PRIMARY SCHOOL STUDENTS IN CHINA
}

\author{
Stanislav Naumenko
}

\section{H. S. Skovoroda Kharkiv National Pedagogical University, Ukraine}

\author{
stanislav.naumenko2020@gmail.com
}

\begin{abstract}
In China, a Key National Strategy has been developed. According to the Strategy, education is refocused on high quality, the development of a holistic approach to the harmonious development of pupils' personalities, which should be imbued with the spirit of innovation, business skills and develop moral, intellectual, physical, and aesthetic aspects. The Ministry of Education of China also supported the position of an individual approach to each pupil and considering his physical and psychological development. The reform aims to create a favorable educational environment for the development of each pupil, active research training, increasing the flexibility and diversity of courses. Among all the subjects of the educational program, literacy is defined as the most fundamental for the successful assimilation of other educational areas and the holistic development of children's personalities, an indispensable strategy for preserving cultural heritage, national unity, and creativity. The program defined the principles of training. They are: to involve all pupils in the educational process and develop their intellectual abilities, to understand the peculiarities of language and literature education, to promote independent learning, joint learning, and learning based on pupils' requests, to take into account their differences and learning needs, to
\end{abstract}


create curricula based on openness and viability. Such positive changes in pedagogical practice create a favorable educational environment that adapts to different rates of pupil learning. The program aims to develop a wide range of pupils' skills, such as literary literacy, financial literacy, mathematical literacy, and scientific literacy. The program provides an inclusive educational environment that can engage gifted pupils in terms of pedagogical strategies (e.g., individualized learning, research learning, and independent learning), enriched reading materials, and dynamic, multiple assessments). The main problems of implementing the new literacy program are: insufficient teacher competence, the difficulty of transforming deep traditions from the pedagogy of transmission and collectivism to the pedagogy of constructivism, the large class size in China leads to overload of teachers.

Keywords: giftedness; pupils; education; primary school; curriculum; continuing education; teacher training; education system.

\section{Relevance of the research}

Literacy is important for the development of every person, as well as for the prosperity of human society as a whole (UNESCO 2004; 2017). For elementary school students, literacy is not only about learning language and literature, but is also a fundamental ability to succeed in the educational program as a whole. When studying different subjects, students need to know the language to understand, express and formulate their ideas, and linguistic experience can be expanded through different areas of the educational program. With literacy, a person can feel the irreplaceable life pleasure of reading a variety of texts. Over the past few decades, the United Nations has paid close attention to raising literacy for all, emphasizing the fact that literacy is an integral part of the fundamental human right to education. According to UNESCO (2017), literate people have the ability to learn throughout life, as their capabilities allow them to access a variety of social and educational opportunities in times of rapid change in society. With literacy, a person can communicate with others, gain access to social resources, participate in social activities and gradually become an autonomous person, think critically and understand the world. At this point the development of literacy contributes to social justice, democratic processes, and the well-being of people (Rassoul, 1999). Therefore, it is important for society in general and schools in particular to respond to the needs of everyone who learns in the development of their literacy skills. Special attention in this aspect should be paid to gifted students, as they need special training programs. In this aspect, it is valuable to study the experience of leading countries, including China, which has a long 
tradition of teaching and educating gifted children, and in recent years has taken a leading position in many fields of science, economics, production.

\section{Analysis of previous research}

It is established that the issues of literacy of gifted children have been the subject of many scientific investigations by both national and foreign scientists. Thus, C. Bonds and L. Bonds (1983), S. Reis, E. Gubbins, C. Briggs, F. Schreiber, S. Richards, J. Jacobs and J. Renzulli (2004) studied the characteristics of children who read faster than is provided by standard levels for a certain age or have the potential for rapid progress in reading, considering such children as "gifted readers". Theoretical studies of gifted students, such as G. Gardner's Theory of Multiple Intelligence and F. Gagnier's Differentiated Model of Giftedness and Talent, identify intelligence or natural abilities that are specifically related to language acquisition and literacy. In addition, numerous studies (D. Weigel, S. Martin and K. Bennett (2006); A. Baroody and K. Diamond (2016); E. Bergen, T. Zuijen, D. Bishop and P. Jong (2017) and others) find that a literacy environment built by the family, school, and society can contribute to the high achievement of gifted children. These environmental factors shape the readiness of children to study at school, to acquire various educational competencies that children will demonstrate during school.

S. Reis and co-authors note that gifted students master literacy faster and easier, memorize large amounts of information, use higher-order thinking skills more often, understand abstract ideas, and demonstrate a high ability to solve problems. They read with pleasure, appreciate the beauty of reading, read creatively and critically, and are able to indulge in reading activities (Reis and all., 2004). J. Simpson's research has shown that due to effective reading skills, the cognitive abilities of gifted readers are above average (Simpson, 2017). At the same time, it should be noted that the issues of teaching literacy to gifted children in the People's Republic of China remain insufficiently covered in the national scientific and pedagogical thought.

The aim of the article is to analyze the literacy program for gifted children in China at the present stage of development of the society.

\section{Presenting main material}

Since the foundation of the People's Republic of China in 1949, China has undergone significant social changes and transformations on the way to building a modernized country. Recognizing the importance of education, the Chinese government passed the Compulsory General Education Act (1986) and published a number of national strategies and plans. In particular, these are: Guidelines for Education Reform and Development (1993), Decisions on 
Deepening Education Reform (2000). This contributed to the popularization of basic education in China, raising the level of literacy of the population and the development of skilled labor. The level of primary school enrollment in primary school children increased from $20 \%$ before the creation of the PRC to $97.9 \%$ in 1990 and $99.92 \%$ in 2016; the incomplete secondary school enrollment rate increased from 6\% in 1949 to $98.7 \%$ in 2016 (CPG, 2013).

Although China has made significant progress in general education, it constantly needs to address issues such as the poor quality of teaching and learning, large population, limited resources and inequality in education. In addition, China's education system is more examoriented, centralized, and standardized. In 2010, a "Summary of China's National Plan for Medium- and Long-Term Education Reform and Development for 2010-2020" was published. It emphasizes the need to consolidate primary and secondary education by 2020 . In addition, the report states that education stakeholders should focus on ensuring the same level of education in rural and urban areas for all, regardless of origin. At the same time, the quality of education had to be improved in order to improve students' ideological awareness and academic performance. During this period, education in China faces serious challenges, including an underdeveloped system of pedagogical knowledge in much of the teaching staff, imperfect curricula and teaching resources, limited funding for education, and a shortage of teachers who could respond to student needs and social change (CPG, 2010). ). This basic knowledge should help to understand the existing teaching practices for gifted children in Chinese primary school.

The modern Chinese education system consists of five levels, of which nine years of primary and lower secondary school are compulsory for every school-age child under the Education Act (CPG, 2006):

- pre-school education,

- 6 (or 5) years of primary education,

- 3 (or 4 ) years of incomplete secondary education,

- 3 years of secondary education (focused on academic education) or vocational education (job-oriented),

- Higher Education. In order to receive free compulsory education, most schoolaged children must attend a public school in their area of residence. Entrance exams are not usually held at this stage, and unlike most Western countries, where primary school teachers are responsible for the class and most subjects, every primary school teacher in China is responsible for a major subject, such as literacy or math, in several classes. In Chinese 
communist society, most primary schools are public. They make $96.6 \%$ of all primary schools and provide education for $92.4 \%$ of all primary school students. Public schools in China are owned by government agencies and tend to have a fairly positive reputation among parents and students.

After compulsory education, Chinese students can choose to attend high school or vocational education. To enter the basic high school, students must demonstrate high results in regional standardized entrance exams with an academic orientation. To enter the best universities, prospective entrants must work hard to prepare for the National College Entrance Examinations (NCEE) in high school. NCEE performs the same function as Keji's old system of talent screening across the country. NCEE has also adopted some of Keji's key features, such as academic orientation, assessment of existing knowledge, and mechanical memorization (Dello-Iacovo, 2009). The competition for exams is very fierce, and students and their families see these exams as the most important or even the only way to social mobility.

Although there are no entrance exams at the primary stage, the exams for upper secondary and higher education still have an impact on teaching and learning in primary schools. Thus, in China's education system, exams focus on intellectual abilities and thus sometimes ignore other needs and diverse talents of students. At the current level of higher education pedagogy, teaching materials, teacher-student relationships, physical training and learning styles are all subject to and determined by school examinations (Kirkpatrick, 2011). Numerous empirical studies have shown that pedagogy focused on writing textbooks and manuals for exams is still widespread in Chinese schools (Kirkpatrick, 2011).

Thus, in modern Chinese schools, less attention is paid to the development and encouragement of critical and creative thinking of students, because the evaluation criteria focus more on factual knowledge.

Extended learning opportunities and resources outside the curriculum and exam content are considered less important, and teaching methods focus on exam requirements rather than the effective development of gifted students. Thus, education for gifted people in China is mainly concentrated in powerful universities, as studying there is not aimed at successfully passing certain standardized exams, so the elements of education for gifted people, such as diversity, innovation, higher thinking, practical skills and self-study training can be allowed and supported. Despite the fact that most Chinese schools have an examoriented approach, and not all schools use innovative learning strategies for students, especially for the gifted (Fu, 2017), the country has long been aware of the problem of 
limiting opportunities for individual development. The education system in China has undergone several waves of pedagogical reforms over the past few decades. In the late twentieth century. A key national strategy was developed, according to which education ceased to focus on academic tests and intellectual abilities, and was refocused on quality, the development of a more holistic approach to the harmonious development of students who need to innovate, acquire business skills and develop moral, intellectual, physical and aesthetic aspects of one's personality (MOE, 1999). The Ministry of Education of China also supported the position of individual approach to each student and taking into account his physical and psychological development. It seems that the whole education system in China is transforming from the evaluation of talents filled with factual knowledge to the evaluation of talented people with creative and innovative potential (Zhang, 2017).

One of the key areas of quality education is the reform of curriculum for basic education (including preschool, primary and secondary education). In 2001, a key document was published - the Curriculum Reform Plan for Basic Education (trial). This paper addresses a wide range of basic education issues, such as school management, teaching materials, teacher evaluation and training (MOE, 2001). The reform aimed to create a favorable environment for the flexible development of each student, including the gifted. It aims to engage each student in active research learning instead of passive and mechanical memorization, increase flexibility and variety of courses to meet individual educational needs of students and shift the focus of the assessment function from identification to the process of student development. Decentralization of discipline management has also been emphasized in order to increase the adaptability of curriculum for students from different regions, schools and with different functions (MOE, 2001). The result of this reform was the spread of progressive social thinking in education, the implementation of various experimental projects that are successful and inspiring for the development of various abilities and personalities of students.

Among all the subjects of the educational program to be reformed, literacy as the most fundamental ability is in the center of attention. We propose to consider the literacy curriculum for gifted students in a primary school in China. Due to quality-oriented education reform, in 2001 the Ministry of Education of China published a trial version of the "Standards of the Chinese Language Curriculum and Literacy for Compulsory Full-Time." After ten years of intensive experiments and practices, in 2011 it was improved and adopted as a final, complete and modern version. The literacy curriculum conceptualized literacy as the most fundamental area of study for the successful assimilation of other educational areas and the 
holistic development of children's personality, an indispensable strategy for preserving cultural heritage, national unity and creativity (MOE, 2011). Thus, the development of literacy of each student has personal and national significance, although they may have different abilities and interests in the field of literacy.

Note that the formation of a new curriculum was significantly influenced by Western education and philosophy. Following the example of many Western curriculum, the Chinese curriculum indicates that teaching and learning in the regular classroom should be studentcentered rather than teacher-oriented (MOE, 2011). This thinking has become revolutionary for China, because in traditional Chinese culture and society, the teacher was treated as an authoritative carrier and transmitter of knowledge, and therefore the teaching system was focused on the teacher. Student-centered learning is reflected in four guidelines:

- involve all students in the educational process and comprehensively develop their intellectual and emotional character;

- understand the features of language and literary education;

- to promote independent learning, joint learning and learning on the basis of requests, to take into account individual differences and needs of students in education;

- create curriculum based on openness and viability, support the needs of different regions, schools and individuals, regulate and improve the structure (Ruan, 2012). Although the curriculum does not clearly state what the differences may be between people, and does not raise the issue of gifted students, these principles ensure that giftedness is taken into account in learning. Such positive changes in educational practice create a favorable environment that is able to adapt to different rates of learning of different students. Curriculum stipulates that the teaching and learning of literacy should be carried out using information technology. This means that for the learning of gifted students and all other children, reading and self-study can be practiced online and, in addition to literacy textbooks, a wide range of ICT-based reading texts can be used, such as books with digital applications. moving images, audio books to enrich their reading experience. They have to improve their intensive reading as well as extensive reading.

As part of this curriculum, local authorities or schools are encouraged to select series of textbooks as the main resource for literacy training. Requiring teachers to use textbooks could standardize teaching and provide a systematic way to teach literacy. However, it can also jeopardize the development of gifted students, as the concise texts and standardized content of the textbook may not meet their individual abilities and educational needs and may not fully stimulate optimal learning in regular classrooms. Thus, the balanced use of 
textbooks and additional resources to improve literacy is crucial for the development of all students. Curricula also encourage teachers and schools to create and develop resources to increase the literacy of local communities in public places, such as theaters, nature parks, museums, the Internet, and even on billboards. The program states that literacy education should be interdisciplinary, responsive to societal change, and related to children's lives (MOE, 2011). Thus, the curriculum encourages teachers when planning the educational process to anticipate the development of a wide range of students' skills: literary literacy, financial literacy, mathematical literacy and scientific literacy.

One of the important text forms is classical Chinese poetry, as students are required to memorize and read a large number of them in order to better understand traditional Chinese language and culture.

Assessment of reading skills, as required by the curriculum, should take various forms. Standardized tests do not have to be the only method of assessing students; modern programs offer a combination of classroom observation, questionnaires, interviews, peer assessment, and self-assessment (MOE, 2011). The curriculum also states that the purpose of the various forms of assessment is to facilitate the learning of students, not to select and rank them. Through dynamic feedback through assessment, teachers can change the pace of teaching and the content of the teaching material as needed and according to the needs of the students. This approach to assessment is consistent with the position of K. Tomlinson, who argues that for the development of students, especially gifted, it is necessary to provide continuous monitoring assessment and, given its results, flexibly and quickly adjust the content and methods of literacy. A system of three-level exams was developed: a county-level exam, which gave the right to receive the first scientific degree, a provincial-level exam - the second scientist. Thus, the future professional growth of each Chinese child depended on education, creativity and intellectual talent. Note that the negative aspect of the theory of Confucianism was the division of society into two components - people of mental and people of physical labor. Thus, the follower of Confucius Meng Tzu emphasized that "people of intellectual labor" should lead "men of physical labor", which negatively affected the level of tolerance in Chinese society at the time and became part of the Chinese tradition until the twentieth century.

It can be argued that, in theory, the curriculum can provide an inclusive learning environment that is able to engage gifted students in terms of pedagogical strategies (eg, individualized learning, research learning, and independent learning), enriched reading materials, and dynamic assessment in a variety of forms. However, in practice, various studies 
show that Chinese teachers have faced serious problems in implementing the curriculum since the beginning of the reform of quality-oriented education. In general, the Chinese education system is still exam-oriented, and many teachers still prefer to use reproductive teachingoriented methods instead of new student-centered pedagogical strategies. It is difficult for teachers and schools to transform their deep pedagogical traditions of retransmitting readymade knowledge and collectivism to the Western pedagogy of constructivism. In particular, with limited training and support, many teachers, with the exception of teachers from elite schools and economically developed regions, are not competent enough to determine the importance of the pedagogical techniques offered in the new curriculum. At the same time, it should be noted that overcrowding in China leads to overcrowding, insufficient funding for the implementation of the new pedagogical doctrine, and limited places for senior secondary and higher education - all this hinders the implementation of a new definitely progressive curriculum. The curriculum still focuses on the use of textbooks, and teachers are sometimes forced to hastily present material in order to "catch up" with the program, leaving little time for additional materials that would enrich the content and stimulate independent learning of students. These problems can have a particularly painful effect on the learning of gifted students. As there is a lack of research on the pedagogical support of gifted students in the transition phase of Chinese education, it is important to support and stimulate research in the field of gifted students.

\section{Conclusions}

In modern Chinese schools, assessment criteria focus more on factual knowledge, and learning opportunities outside the program are considered less important. At the end of the twentieth century, a key national strategy was developed, according to which education ceased to focus on academic tests and intellectual abilities, and was refocused on the harmonious development of personality, individual approach to each student. The reform aims to involve each student in active research learning instead of passive and mechanical memorization. The literacy curriculum conceptualized literacy as the most fundamental area of study for the successful assimilation of other educational areas and the holistic development of children's personality, an indispensable strategy for preserving cultural heritage, national unity and creativity. The following principles of teaching are defined: to involve all students in the educational process, to develop their intellectual and emotional character, to understand the peculiarities of language and literature education, to promote independent learning, joint learning and learning based on requests, to take into consideration individual differences and learning needs. based on openness. The curriculum is designed to 
develop a wide range of students' skills, such as literary literacy, financial literacy, mathematical literacy and scientific literacy. The program provides an inclusive educational environment based on individualized learning, research learning, and independent learning. The main problems of implementing the new literacy program are: insufficient competence of teachers, the difficulty of transforming deep pedagogical traditions of retransmission of ready knowledge and collectivism to the pedagogy of constructivism, high class size in China, which leads to overload of teachers.

Prospects for further exploration are to study the peculiarities of the education of gifted children in secondary and high school in China, to clarify the forms, methods and means of teaching gifted students.

\section{References:}

1. Baroody, A. E., \& Diamond, K. E. (2016). Associations among Preschool Children's Classroom Literacy Environment, Interest and Engagement in Literacy Activities, and Early Reading Skills. Journal of Early Childhood Research, 14(2), 146-162.

2. Bergen, E., Zuijen, T., Bishop, D., \& Jong, P. F. (2017). Why Are Home Literacy Environment and Children's Reading Skills Associated? What Parental Skills Reveal. Reading Research Quarterly, 52(2), 147-160.

3. Bonds, C. W., \& Bonds, L. T. (1983). Teacher, is There a Gifted Reader in First Grade? Roeper Review, 5(3), 4-6.

4. CPG. (2010). Outline of China's National Plan for Medium and Long-term Education Reform and Development 2010-2020, 2010. Retrieved from: http://www.gov.cn/jrzg/2010-07/29/content_1667143.htm [in Chinese]

5. CPG. (2013). The Status of Educational Development in China. Retrieved from: http://www.gov.cn/test/2005-09/07/content_29930.htm [in Chinese]

6. Dello-Iacovo, B. (2009). Curriculum reform and "Quality Education" in China: An overview. International Journal of Educational Development, 29, 241-249.

7. DOI: https://doi.org/10.1186/2229-0443-1-3-36

8. Fu, T. (2017). Wandering in the Shadow of Egalitarianism and Equity: A Social and Cultural Explanation to the Underdeveloped Gifted Education in China. Global Education Review, 4(1), 34-44.

9. Gagné, F. (1985). Giftedness and Talent: Reexamining a Reexamination of the Definitions. Gifted Child Quarterly, 29(3), 103-112. 
10. Gagné, F. (1995)/ From giftedness to talent: A developmental model and its impact on the language of the field. Roeper review, 18(2), 103-111.

11. Gagné, F. (2010)/ Motivation within the DMGT 2.0 Framework. High Ability Studies, 21(2), 81-99.

12. Gardner, H. (1983). Frames of Mind: The Theory of Multiple Intelligences. New York : Basic books.

13. Kerr, B. (Ed.). (2009). Encyclopedia of giftedness, creativity, and talent. Thousand Oaks, CA: Sage. (Vol. 2).

14. Kirkpatrick, R., \& Zang, Y. (2011). The Negative Influences of Exam-oriented Education on Chinese High School Students: Backwash from Classroom to Child. Language Testing in Asia, 1(36).

15. Kyrychenko, S.V. (2016). Orhanizatsiino-pedahohichni zasady roboty z obdarovanymy ditmy v systemi osvity Avstralii [Organizational and pedagogical principles of work with gifted children in the education system of Australia]. dys. ... kand. ped. nauk. Natsionalnyi pedahohichnyi universytet imeni M.P.Drahomanova. Kyiv. 288 s. (in Ukrainian)

16. Melyksetov, A.A. (2002). Istoryia Kytaia [History of China]. Moskva : Vysshaia shkola, 2002. 476 s.(in Russian)

17. MOE. (1999). The Decision of the State Council of the Central Committee of the Communist Party of China on Deepening Education Reform and Comprehensively Promoting Quality-oriented Education. Retrieved from: http://old.moe.gov.cn//publicfiles/business/htmlfiles/moe/moe 177/200407/2478.html_[in Chinese]

18. MOE. (2011). Outline of the Curriculum Reform for Basic Education (Trial). Retrieved from: http://old.moe.gov.cn//publicfiles/business/htmlfiles/moe/moe_309/200412/4672.html

19. Reis, S. M., Gubbins, E. J., $\quad$ Briggs, C. J., $\quad$ Schreiber, F. J., $\quad$ Richards, S., Jacobs, J. K., \& Renzulli, J. S. (2004). Reading Instruction for Talented Readers: Case Studies Documenting Few Opportunities for Continuous Progress. Gifted Child Quarterly, 48(4), 315-338.

20. Ruan, J., \& Jin, L. (2012). Primary School Chinese Language and Literacy Curriculum Reforms in China After 1949. In Perspectives on Teaching and Learning Chinese Literacy in China (pp. 129-140). New York \& London: Springer Science+Business Media Dordrech, 2012. DOI: https://doi-org.ezproxy.lib.gla.ac.uk/10.1007/978-94-007-4822-4. 
21. Simpson, J. (2017). Literacy and the Gifted. In Culturally Relevant Teaching: Preparing Teachers to Include All Learners (pp. 29-42). London: Rowman \& Littlefield.

22. Skylor Zhitian Zhang. Gifted education in China. Zhang, Cogent Education, 2017. № 4. pp. 1-12.

23. The Central People's Government of People's Republic of China (CPG). (2006). Education Law of the People's Republic of China. Retrieved from: http://www.gov.cn/flfg/2006-06/30/content 323302.htm [in Chinese]

24. Tomlinson, C. A. (2014). The Differentiated Classroom: Responding to the Needs of All Learners. Alexandria, VA: ASCD.

25. Weigel, D. J., Martin, S. S., \& Bennett, K. K. (2006). Contributions of the Home Literacy Environment to Preschool-aged Children's Emerging Literacy and Language Skills. Early Child Development and Care, 176(3-4), 357-378.

26. Zhang, Z. (2017). Gifted Education in China. Cogent Education, 4(1). DOI: https://doi.org/10.1080/2331186X.2017.1364881

27. 丁泪, 吉爱明 [DingSi, JiAiming]. (2008). 《有教无类»辨义[《Education but not class» Distinction]. 连云港师范高等专科学校学报 [Journal of Lianyungang Normal College]. p.36-38. (in Chinese)

28. 中華人民共和國革命法第十九條 [Article 19 of the Revolutionary Law of the People's Republic of China]. /https://www.6laws.net/6law/lawgb/\%E4\%B8\%AD\%E8\%8F\%AF\%E4\%BA\%BA\%E6\%B0 \%91\%E5\%85\%B1\%E5\%92\%8C\%E5\%9C\%8B\%E6\%95\%99\%E8\%82\%B2\%E6\%B3\%95.ht $\mathrm{m}$ (in Chinese)

29. 施建农 [Shi Jiannong]. (2001). 为什么要开展超常教育 [Why carry out extraordinary education]. 现代特殊教育 [Modern special education]. 12. 4.(in Chinese)

30. 魅力中国. 校园才艺展示活动 [Charming China-Campus Talent Showcase]. (2012). 通知 [Notice]. (in Chinese) 